\title{
An Experiment on Coasian Bargaining over Ex Ante Lotteries and Ex Post Rewards
}

Jason F. Shogren

Working Paper 90-WP 63

July 1990 


\begin{abstract}
We examine Coasian bargaining under uncertain payoff streams. Subjects bargained over both an ex ante lottery and the ex post reward. The results indicate nearly 87 percent of all agreements were Pareto efficient. However, only 7.3 percent were mutually advantageous, while nearly 85 percent of all agreements split the reward equally. Consequently, we remain cautious about policy recommendations based on the Coase theorem where uncertain payof $f$ exist. Finally, we find no evidence supporting the proposition that a fundamental difference exists between bargaining behavior over the ex ante lottery and the ex post rewards of an uncertain event.
\end{abstract}




\section{Introduction}

Coase (1960) envisioned a world in which two self -interested parties will bargain to a mutually advantageous, Pareto-optimal level of an externality regardless of initial unilateral property right entitlements. The power of Coase's world rests in the decentralized attainment of efficient resource allocation even in the presence of market failure. The potential policy implications of the so-called Coase theorem are enormous. If the Coase theorem is robust, then the role of a third party (e.g., the state) is reduced to simply assigning unambiguous unilateral property rights which facilitate private bargaining and economic efficiency.

Beginning with Hoffman and Spitzer (1982) and Prudencio (1982), several experimental studies have argued that the Coase theorem is quite robust. ${ }^{1}$ In general, the studies have supported the two key behavioral outcomes implied by Coasian bargaining: (i) two parties will agree on a Pareto-optimal level of an externality, and (ii) the agreement will be obtained through mutually advantageous bargaining between two parties. As Harrison et al. (1987) note the Coase theorem is "behaviorally 'alive and well' in relatively sterile and abstract bargaining environments."

The experimental studies have been reluctant, however, in proposing policies for the naturally occurring environment. A major reason is most monetary payoffs (profits or damages) in the natural environment involve some degree of uncertainty. ${ }^{2}$ In contrast, Coase experiments have been designed such that payoffs are known with complete certainty. The two parties bargain over the selection and distribution of a deterministic payoff stream. ${ }^{3}$ Consequently, both Hoffman and Spitzer (1985b) and Harrison et al. (1987) warn against overextending the robust experimental results to environments where payoffs are uncertain. ${ }^{4}$

The purpose of this paper is to examine the robustness of Coasian bargaining under uncertainty. We consider whether individuals behave differently when bargaining over the two key elements that define an uncertain event: the lottery representing the likelihood the event will occur and the reward received if the event does occur. To examine this issue, we construct two distinct bargaining sessions: ex ante lottery bargaining and ex post reward bargaining. Ex ante lottery bargaining exists when two parties bargain over the distribution of lottery tickets that 
determine the likelihood of winning a fixed reward. Ex post reward bargaining exists when two parties bargain over the distribution of the resulting reward given a fixed lottery schedule.

Both bargaining sessions use simple and compound lottery games. A simple binary lottery game is a one-stage lottery where the winner of a deterministic monetary reward is uncertain. A compound binary lottery game is a two-stage lottery where both the winner and the amount of the reward is uncertain. The simple and compound lotteries are used to capture bargaining behavior under differing degrees of uncertainty.

The experimental results answer the following four questions: (1) Does Coasian bargaining remain Pareto-optimal under uncertainty? Yes, Coasian bargaining remains highly efficient even under uncertain payoff streams. With 86.6 percent of all bargaining agreements achieving the joint maximum payoffs, our evidence provides further support for the weak behavioral form of the Coase Theorem.

(2) Does Coasian bargaining remain mutually advantageous under uncertainty? No, under uncertainty the bargainers tended to pool risk rather than seek mutually advantageous outcomes. Nearly 84.2 percent of all agreements essentially agreed to pool the risk and equally split the payoff or chances to win the reward even though this implied a disadvantageous bargain to the controller relative to the expected payoff without a bargain. ${ }^{5}$ Note that to examine mutually advantageous bargaining we tested the assumption that the reduction in returns obtained by the controller was not simply a "mutually advantageous" tradeoff for greater certainty by explicitly monitoring the risk preferences of the subjects. Consequently, our evidence does not support the strong behavioral form of the Coase Theorem.

Bargainers acting more like "fairmen" than "gamesmen" is supported by recent experimentation on Nash-axiomatic models and Rubinstein-strategic models of bargaining [see Roth (1988) and Thaler (1988b)]. As Thaler (1988b) notes one conclusion which emerges is that non-monetary arguments such as fairness can play a significant role in determining the outcome of bargaining. Individuals will walk away from profitable outcomes if offered insultingly low rewards. Alternately, as argued in Shogren (1989), the equal splits may be due to a lack of well- 
defined loyalties between bargainers. When loyalties are well defined in a team style experiment, then bargainers achieve mutually advantageous splits in nearly 86 percent of the bargains.

(3) Is there a significant behavioral difference in Coasian bargaining over ex ante lotteries and ex post rewards? No, given our sample there was no significant statistical difference in bargaining over ex ante lotteries and ex post rewards. This holds for both behavioral outcomes of Pareto efficiency and equal split of rewards and lottery tickets. The result sharply contrasts individual behavior when valuing reduced risk in experimental asset markets [Shogren (1990)]. Individuals valued a change in lotteries significantly more than a change in rewards. Our Coasian bargain experiment suggests that a fundamental difference might not exist in individual behavior toward the lottery and the reward of an uncertain event. Alternatively, the experimental institution may well influence individual preferences over outcomes relative to preferences over lotteries over outcomes. Therefore, observed differences may be institution-specific.

(4) Does increased uncertainty affect the robustness of Coasian bargaining agreements? No, there was no significant statistical difference in bargaining over the simple lottery and the compound lottery. Again this holds for both behavioral outcomes of Pareto efficiency and the equal splitting of rewards and lottery tickets. Individuals pooled risk similarly for both the simple and compound lottery. Greater uncertainty did not create basic differences in bargaining behavior over lotteries and rewards.

The paper proceeds as follows. Section 2 develops the binary lottery games used for the experiment. Section 3 describes the experimental design, and Section 4 presents the results. The conclusions are discussed in Section 5.

\section{Coasian Bargaining and Binary Lottery Games}

In general, a Coase experiment must satisfy Hoffman and Spitzer's (1982) well-defined set of assumptions: (a) two parties to each bargain, (b) perfect knowledge of one another's utility functions, (c) perfectly competitive markets, (d) zero transactions costs, (e) costless court system, (f) profit-expected utility-maximizing consumers, ( $g$ ) no wealth effects, and (h) parties will strike mutually advantageous bargains in the absence of transactions costs. Given assumptions (a) through (g), assumption (h) creates two testable behavior outcomes of Coasian bargaining: 
Pareto-optimal agreements between two parties and the agreements are mutually advantageous. We focus on these two outcomes in testing Coasian bargaining under uncertainty.

Following Roth and Malouf (1979), we construct a binary lottery to control for risk preference. First, consider the ex ante bargaining session where two parties bargain over the distribution of lottery tickets. Let $L=[p R ;(1-p) r]$ be the simple lottery where party $A$ has probability $p$ and $(1-p)[0 \leq p \leq 1]$ of winning $R$ or $r, R>r$. After normalizing each party's utility, $U(R)=1$ and $U(r)=0$, party A's expected utility equals $p$ [Roth (1987)]. Party B's expected utility equals $(1-p)$ for a Pareto efficient bargain or $(1-p-Q)$ otherwise, where $Q$ is probability neither party wins. ${ }^{6}$

The compound lottery adds a second stage where now A's expected utility equals pq, where $q$ is the probability of winning second stage. Party B's expected utility equals ( $1-p) q$ for a Pareto efficient bargain or (1-p-Q)q otherwise. The compound lottery is used to examine bargaining behavior under increased uncertainty. As is evidenced by the so-called "Winner's Curse", not all winners of lotteries or auctions are guaranteed a large reward. ${ }^{7}$ Often the winner of a lottery will find the realized reward substantially less than expected. The compound lottery captures the increased uncertainty but still allows the party's utility to be determined. Finally, the disagreement reward $D$ equals $r$, thereby providing no incentive for one risk averse party to hold out for $\mathrm{D}$.

In the ex post bargaining session, two parties bargain over the distribution of the large reward. For example, party A might agree to receive 40 percent of the large reward if either party $A$ or $B$ wins. Let $Z(r \leq Z \leq R)$ be the amount of the reward $A$ receives with probability $\bar{p}=1$ for a Pareto efficient bargain, $\bar{p}=p+(1-p-Q)$ otherwise. Party A's expected utility then is $\bar{p} U(Z)=U(L)=p$. Therefore, for a Pareto-efficient outcome party A's utility from receiving $Z$ equals p. Party B's utility from receiving $Z$ equals $(1-p)$. In this case, $Z$ is the certainty equivalent of playing the lottery. To determine mutually advantageous bargaining, we explicitly monitor each individual's certainty equivalent for expected payoffs without bargains. We describe this process in the next section. 
In the ex post compound bargaining sessions, since both parties agree to receive some $\mathrm{Z}$ ( $\mathrm{r}$ $\leq Z \leq R)$ with probability $p^{\prime}=p q+(1-p-Q) q \leq q$, Party A's utility is $p^{\prime} U(Z)=U(L)=p q$. If a Pareto-efficient agreement is reached, then $p^{\prime}=p q+(1-p-Q) q=q$, and Party A's utility from receiving $Z$ equals the probability of receiving the large reward p. Party B's utility of receiving $\mathrm{Z}$ when $\mathrm{p}^{\prime}=\mathrm{q}$ is equal to $(1-\mathrm{p})$. Again, if two parties cannot come to an agreement in the allotted time, the disagreement reward equals the small reward, $D=r$.

Given the Coasian assumptions (a)-(h) and the binary lottery games, four propositions will be considered to test the robustness of Coasian bargaining under uncertainty.

Pareto-Optimum Proposition (P1): Two parties will bargain to a Pareto-optimal lottery schedule under uncertain monetary payoffs.

Mutually Advantageous Proposition (P2): Two parties will bargain to a mutually advantageous agreement over distribution of lottery tickets or rewards under uncertainty.

Acceptance of propositions $\mathrm{P} 1$ and $\mathrm{P} 2$ will support robust Coasian bargaining even under uncertainty. If $\mathrm{P} 1$ and $\mathrm{P} 2$ are not accepted, however, then the general Coase theorem is not universally applicable to bargaining under uncertain monetary payoffs. Since most natural environments involve uncertainty to some degree, nonacceptance will continue to restrict the applicability of Coasian bargaining to policy decisions.

Lottery-Reward Proposition (P3): There is no behavior difference in Coasian bargaining over ex ante lotteries and ex post rewards.

Rejection of P3 will support the view that a significant difference exists in individual behavior toward lotteries and rewards. Shogren (1990) found evidence that individuals value changes in the lottery significantly higher than changes in the reward of an uncertain event. The lottery change was preferred to the reward change due to a certainty effect. In the lottery change, the individual was guaranteed a certain gain with no loss. The reward change, however, guaranteed no loss but did not guarantee a gain. Therefore, the lottery change was valued significantly higher than the reward change. 
Given the basic structured differences in the ex ante lottery and ex post reward bargaining one might suspect a similar difference in behavior. The lottery bargain implies only one party will win the large reward, $R$. With the reward bargain, both parties have the potential to receive some payoff, $Z$. Although according to the Coase theorem, both bargains should be efficient and mutually advantageous, lottery bargaining may be more competitive. The all-or-nothing nature of the lottery bargain may lead to more mutually advantageous bargains than the ex post severity bargains. Indeed, if this is the case, Shogren's (1990) findings are supported and a fundamental difference may exist in bargaining before and after uncertainty is resolved. If P3 is not rejected, however, then the robustness of Coasian bargaining is independent of whether parties bargain before or after uncertainty is resolved.

Increased Uncertainty Proposition (P4): There is no behavioral difference in Coasian bargaining in simple versus compound binary lottery games.

Acceptance of P4 suggests the robustness of Coasian bargaining is independent of the degree of uncertainty. Coasian bargaining in the experiments would have a similar strength or weakness. If $\mathrm{P} 4$ is not accepted, then further experimentation is warranted to determine if a boundary exists of robust Coasian bargaining under uncertainty.

\section{Experimental Design and Procedures}

To the extent possible, the experimental design and procedures follow Hoffman and Spitzer (1982) and Harrison and McKee (1985). All subjects were undergraduate students at Appalachian State University, and were considered inexperienced bargainers, i.e., no subject had participated in a Coasian bargaining experiment. As the subjects entered the lab, each was randomly assigned to be either party $\mathrm{A}$ or party $\mathrm{B}$.

Each subject was given an identical set of instructions. ${ }^{8}$ The subjects were told they would participate in two successive bargaining sessions, each session with a different opponent.

Opponents differed to reduce sharing behavior and altruism, thereby increasing the incentive for mutually advantageous bargaining [see Harrison and McKee (1985)]. Each bargaining session was face-to-face, public, and had a ten minute time constraint. No physical threats were allowed. A 
monitor was present for each session. The monetary payoffs were public but only after completion of both sessions.

Subjects participated in either the simple or the compound lottery, not both. Regardless of the lottery game, each subject participated in one ex ante lottery and one ex post reward bargaining session. Each session had an agreement outcome and a disagreement outcome. The agreement outcome required agreement by the two parties on (i) which number to select from a lottery schedule reflecting each party's probability of winning the large reward [see Table 1], and (ii) how to distribute lottery tickets which determine the probability of winning a reward (ex ante lottery) or how to distribute the reward (ex post reward). All agreement outcomes required both parties sign a contract stating the number selected and the distribution of lottery tickets or reward. The contracts were perfectly enforced by the monitor.

If two parties could not come to an agreement in the allotted time, then the disagreement outcome was enforced. The disagreement outcome was consistent across bargaining sessions: If two parties could not come to an agreement, both parties would receive the small reward (zero) for that session. The zero payment disagreement outcome controlled for potential risk posturing by the bargainers.

At the start of each session one party, the controller, was given unilateral property rights over the lottery schedule. The controller had complete control over which number was selected from the lottery schedule. The controller could select a number him/herself without agreement from the other party and inform the monitor, who would then end the session. The other party attempted to influence the controller to reach a mutually advantageous decision by offering to give part or all of his lottery tickets or realized reward to the controller.

Following Hof fman and Spitzer's (1985b) experiments on concepts of distributive justice, the controller was determined on a competitive basis. Hof fman and Spitzer found a competitive game trigger increased the incentive for mutually advantageous bargaining. A simple random assignment of controller privileges (e.g., coin flip) increased the likelihood of equal distribution of payoffs. The goal of a competitive game trigger is to bestow the controller "moral authority" 
over the other party. In our experiments, the competitive game trigger was a dot game similar in nature to Hoffman and Spitzer's (1985b) game."

After reading the instructions at least once and listening to the monitor read the instructions once, the subjects were given a set of questions designed to determine their understanding of the instructions. After the subjects correctly answered all questions and all relevant verbal questions were answered by the monitor, the controller was decided and the bargaining began. First, the subjects bargained over ex post rewards, then af ter switching bargaining partners the subjects bargained over ex ante lottery tickets.

Consider a typical efficient bargain in a simple lottery game. Using lottery schedule $\mathrm{X}$ from Table 1, the controller has the option of selecting the number which provides him an expected return of $\$ 8(80$ percent chance of earning $\$ 10)$ and the other party $\$ 0$ expected return, or if both parties agree they could select the Pareto efficient number ( $\# 3$ ) and divide the 100 percent chance of earning $\$ 10$. Coasian bargaining theory would predict that the parties will agree to the number yielding 100 percent chance to win $\$ 10$, with the controller getting no less than the $\$ 8$ expected return.

After both the ex ante and ex post bargaining sessions were completed, the uncertainty about monetary payoffs was resolved. For the simple lottery game, the winner of the ex ante lottery was determined by a random draw of a lottery ticket from an urn. The composition of tickets corresponded to the contractual agreements made between the two parties. The winner received the entire large reward. In the ex post session, a random draw determined the winner, and the reward was distributed to the parties according to the contractual agreement.

In the compound lottery, uncertainty was resolved in two stages. First, the winner of the lottery was determined by random draw, then the amount of the reward, either $R$ or $r$, was determined by a coin flip. The distribution of lottery tickets and the payoffs in the ex ante and ex post sessions correspond to the signed contractual agreements between the two parties.

The Pareto efficient outcome for all ex post sessions guaranteed the subjects an agreed upon reward $(Z)$ with 100 percent certainty [see Table 1]. Since a certain outcome could be achieved, we monitored each individual's risk preference for the lotteries where there was an 80 
9

or 90 percent chance of winning the large reward. These two lotteries reflect the maximum expected reward attainable without bargaining for schedules $\mathrm{X}, \mathrm{Z}$, and $\mathrm{Y}$ [Table 1]. Risk preference was monitored by determining each individual's certainty equivalent for the 80 and 90 percent lotteries [also see Murnighan et al. (1988)]. Accordingly, each subject answered two final questions of the form:

I am indifferent between receiving $\$$ _ with 100 percent certainty and playing a lottery where there is an $80(90)$ percent chance of winning $\$ 10$ and a $20(10)$ percent chance of winning $\$ 0$.

By comparing the individual's certainty equivalent to the agreed upon reward $(Z)$, we can determine if a mutually advantageous bargain has occurred. For example, say a controller bargained to a $50 / 50$ split (\$5) in the ex post session under schedule $X$, but revealed a certainty equivalent of $\$ 7$ for the 80 percent lottery, since $\$ 7$ exceeds $\$ 5$, the controller did not bargain to a mutually advantageous outcome.

\section{Experimental Results}

\subsection{Efficiency}

Table 2 presents the experimental results of Coasian bargaining under uncertain monetary payoffs. The Pareto-Optimum Proposition P1 is supported: 86.6 percent (seventy-one out of eighty-two) of all bargains achieved a Pareto efficient agreement. This result corresponds to the Coasian bargaining experiments under certainty. In a series of experiments, Hoffman and Spitzer (1982, 1985a, 1986) found that 89.5, 91, and 93 percent of bargains were efficient, and Harrison and McKee (1985) found 95.1 percent of all unilateral bargains were efficient. A simple t-test of two population proportions cannot reject the null hypothesis that the efficiency results in our experiments are not statistically different from the Harrison and McKee experiment with the highest efficiency (95.1 percent) with 95 percent confidence $(t=-1.445)$. Consequently, our results support the weak behavioral form of Coasian bargaining even under uncertain payoff streams.

Consistant with previous bargaining experiments, all contracts were perfectly enforced. There was never any doubt the terms of the agreement would be fulfilled with 100 percent certainty. To determine if the high level of efficiency ( 87 percent) was sensitive to the 
probability of contract enforcement, Shogren and Kask (1990) constructed an experimental design incorporating four cases of imperfect enforcement. The evidence suggests Pareto efficiency is directly related to the probability of enforcement. When the probability of enforcement was low, the levels of efficiency declined to a range of 8 to 71 percent. The results suggest that efficiency is influenced more by uncertain contractual enforcement than by uncertain payoff streams. Therefore, how uncertainty enters into the bargaining problem may be as important to efficiency as the level of uncertainty. Future work examining bargaining efficiency should explore the various avenues in which uncertainty can enter into bargaining situations.

\subsection{Distribution of Wealth}

The Mutually Advantageous Proposition P2 is not supported: 84.1 percent (sixty-nine out of eighty-two) of all bargaining agreements split the reward equally or within one dollar of the reward or 10 percent of the lottery tickets. Only in 7.3 percent (six out of eighty-two) of the agreements did the controller achieve or exceed the maximum expected reward attainable without bargaining. The individuals did not follow the predicted behavior of mutually advantageous bargaining. Consequently, the results do not support the strong behavioral form of Coasian bargaining under uncertain payoff streams. ${ }^{10}$

Note the equitable split of rewards and lottery tickets is not solely attributable to Coasian bargaining experiments. Recent experimental work on non-cooperative Nash bargaining has obtained similar results. Although Rubinstein (1982) predicts the controller will make of fers approaching zero and the other party will accept, the evidence is quite the opposite. The other party is quite willing to reject profitable transactions which are perceived as insultingly small offers [see Binmore et al. (1988) and Roth (1988)]. Bargainers end up behaving more like "fairmen" than the "gamesman" theory predicts.

Consider four explanations of nonmutually advantageous bargaining. First, the competitive prebargain game trigger may not have induced a true belief of ownership in the unilateral property right entitlement. Following Hof man and Spitzer (1985a), the dot game trigger was designed to be competitive enough to bestow the controller with a feeling of moral authority over his opponent. Relative to a random coin flip, Hoffman and Spitzer demonstrated a competitive 
game trigger could successfully bring about mutually advantageous bargaining behavior. In our experiments, however, subjects still pooled their risks, dividing the lottery tickets or rewards evenly. Equal splits occurred despite the experimental instructions explicitly stating the controller's "moral authority" over the other bargainer. A plausible explanation is that although the dot game trigger is similar to Hof man and Spitzer's trigger, subtleties exist in competitive triggers which are more important than previously realized. Future research could explore the threshold of prebargain competitiveness necessary to induce a true belief of ownership in a unilateral property right experiment.

A second explanation of equal splits is suggested by Harrison and McKee (1985). They argue that a small social surplus could bring about equal splits. Social surplus is defined as the difference between the maximum joint chance to win (100 percent) and the next best alternative. We tested this hypothesis by comparing the wealth distribution given Schedule $Z$ where the social surplus was 20 percent to Schedules $\mathrm{X}$ and $\mathrm{Y}$ with a surplus of 5 percent [see Table 1]. In contrast to Harrison and McKee, the larger social surplus failed to induce mutually advantageous bargaining. Nearly 87 percent (nineteen out of twenty-two) of the bargains given Schedule $Z$ were essentially equal splits compared to 83 percent (fifty out of sixty) for schedules $\mathrm{X}$ and $\mathrm{Y}$. The social surplus did not seem to be the reason for the equitable distributions. Again future work could consider how large the surplus must be before bargainers are induced to behave as predicted.

A third explanation is that non-monetary concerns such as fairness play a significant role in bargaining behavior [see Hoffman and Spitzer (1985a), Thaler (1988), and Roth (1988)]. Equitable distributions of wealth result from bargaining if the perceived benefits of fairness outweigh the incentive to reach the subgame perfect equilibrium predicted by theory. The idea of egalitarian fairness influencing bargaining is supported by the recent work by Frank (1987), among others, that non-monetary concerns play an important role in an individual's utility function. ${ }^{11}$ Given our experimental design used face-to-face bargains, issues of fairness could possibly play a role in equal splits. Roth (1988) cites evidence that due to social conditioning there is less disagreement with face-to-face bargaining than with anonymous bargaining 
experiments. As a result, Roth questions the appropriateness of face-to-face negotiations in bargaining experiments. Although face-to-face bargaining provides more avenues of uncontrollable communication, one still observes many inequitable distributions in face-to-face bargains in the natural environment. Examples range from labor contract negotiations and arbitrage agreements to haggling in a farmer's market over the price of corn. Face-to-face bargains exist in the natural environment that do not result in equitable distributions of wealth. Consequently, fairness may require more context to be helpful in explaining equal split bargaining.

A fourth explanation, in my mind the most plausible, is the lack of an explicitly defined radius of loyalty. Traditional bargaining experiments, including the one herein, have not controlled for the loyalty of each subject. A bargainer could be loyal only to himself, or his fellow bargainer, or perhaps the world. Therefore, while fairness may be important, the key issue is to whom the bargainer is being fair. Unless the experiment controls for fairness in the context of loyalty, one can not be sure. Consequently, the equal split result may be due to the lack of a well-defined control for loyalty among bargainers.

Shogren (1989) tested the loyalty hypothesis by explicitly controlling loyalty. The experiment replicated the ex ante lottery bargains except now each bargainer was part of a team whose goal was to maximize team wealth. Given rules similar to a team total point boxing or wrestling tournament, each bargainer participated in a simple and compound lottery. Given explicitly controlled loyalties, only 11 percent (nine out of eighty-four) of all bargains remained equal splits of wealth, while nearly 86 percent (seventy-two out of eighty-four) were mutually advantageous outcomes. This result is the opposite of the distribution results obtained without controlling for loyalty. A bargainer shifted his concept of fairness from his opponent to the group of individuals who were dependent on his actions. Note that this occurred even though the team experiments were tilted toward an equal split solution given a random controller assignment (i.e., coin flip) and face-to-face bargains. Note, however, that while team bargainers behave like gamesmen, they were also less efficient than the nonteam bargainers who achieved nearly 87 percent Pareto efficiency. The Pareto efficient agreements declined to 64 percent (fifty-four out 
of eighty-four) in the team experiments. The controller in the team bargain was willing to give up efficiency to make sure the opponent had zero chance of earning any reward.

In summary, equitable splits of wealth and high Pareto efficiency is observed in bargains where loyalties are ambiguous. Given the relative homogeneity of the subject pool, these bargains were generally non-confrontational. The bargainers took an egalitarian or Kantian position where both efficiency and equity were achieved. As the reviewer pointed out, this should be a cause for rejoicing, rather than despair, if it could be relied upon. Perhaps, efficient and equitable bargaining might be observed within tight-knit collectives such as social clubs, families, or the beaches of France [Laffont (1975)]. Unfortunately, the team experiments with explicitly defined loyalties suggest such bargaining may be illusionary. Even though the subject pool remained relatively homogenous, the bargains now became more conf rontational. Efficiency declined by 20 percent and equitable splits were the exception, not the rule. I suspect that if we can explain the threshold that separates the fairman in the individual bargains from the gamesman in the team bargains, we will achieve a better correspondence between observed behavioral and theoretical predictions.

\subsection{Lottery and Rewards}

The Lottery-Reward Proposition P3 cannot be rejected given the results reported in Table 2. Using a Chi-square goodness-of-fit test [see Siegel (1956)] with a 90 percent confidence level, there is no statistical difference in bargaining over ex ante lottery and ex post rewards. Table 3 presents the results of the statistical tests. This result holds for both the weak (Pareto efficiency) and the strong (mutually advantageous bargains) behavioral firms of Coasian bargaining. The result also holds regardless of the lottery (simple or compound) or the social surplus (Schedule $\mathrm{X}$ and $\mathrm{Y}$ or $\mathrm{Z}$ ).

This result suggests no fundamental behavioral difference exists between bargaining over ex ante lotteries and ex post rewards. Individuals were just as likely to bargain efficiently and to split the lottery tickets or reward evenly. This result contrasts the theoretical arguments of Boyer and Dionne (1983) and the risk reduction valuation experiments of Shogren (1990). Boyer and Dionne (1983) argued that in terms of cost-effectiveness an individual would prefer a risk 
reduction in the severity (reward) to a reduction in the probability (lottery) of an undesired event. In contrast, the valuation experiments indicated that individuals were willing to pay more to reduce the probability than the severity of an undesired event. The results of Coasian experiment fail to support either difference in behavior.

The observation of behavioral differences over lotteries and rewards may be experimentspecific; not readily transferable to a broader range of phenomena. The experimental institution couid influence individual behavior. Preferences over outcomes and preferences over lotteries over outcomes could be directly influenced by the institution. In Shogren (1990), preferences were examined using a sealed-bid, second-price Vickrey auction repeated over twelve market trials. The competitive framework with repeated market exposure disciplined the subjects to form values rapidly. Note that the difference in behavior was found in the last trials, not in the initial first trial. In the first trial, values for lottery and reward changes were not significantly different. Given our Coase institution only considered two ten-minute bargains, subjects may not have had adequate exposure to learn the predicted strategy of mutually advantageous positions. Lack of bargaining experience has generally been the case for all Coase bargaining experiments. Given efficient market allocations imply repeated exposure to the market, an interesting extension would be to allow ten or more bargaining opportunities. One could then examine whether bargaining behavior remains consistent, or whether repeated trials significantly influences preferences.

\subsection{Degree of Uncertainty}

The Increase Uncertainty Proposition P4 cannot be rejected given the statistical tests reported in Table 3. There appears to be no significant statistical differences in Coasian bargaining as uncertainty increases. Both the bargainers in the simple and compound lottery were equally likely to be efficient and to pool risks to an essentially equal split of lottery tickets or rewards. Neither the simple nor the compound lottery was sufficient to induce a change toward mutually advantageous bargaining. Risk pooling behavior was equally strong in both lotteries. The (non)robustness of Coasian bargaining is independent of the degree of uncertainty. 


\section{Conclusions}

Coasian bargaining has been examined under uncertain payoff streams. Individuals bargained over both the ex ante lottery of winning a reward and the ex post reward itself. First, the experimental results reported provided mixed support for the Coase theorem. The results strongly support the weak behavioral form of Coasian bargaining in that nearly 87 percent of all agreements were Pareto efficient. The results do not support the strong behavioral form, however, in that only 7.3 percent of agreements were mutually advantageous. Consequently, we must continue to support Hoffman and Spitzer's (1985b) warning about proposing policy recommendations based on the Coase theorem in natural occurring environment possessing any degree of uncertainty regarding monetary payoffs.

Second, the results do not support the proposition that a fundamental difference exists in individual behavior toward ex ante lotteries (or probabilities) and ex post rewards (or severity). We find no behavioral difference in bargaining. Bargaining over both ex ante lotteries and ex post rewards were equally likely to generate Pareto efficient and nonmutually advantageous agreements.

Expanding bargaining behavior to include non-monetary aspects such as loyalty and fairness is open for future exploration. When Coasian bargaining was duplicated using rules similar to a team total point tournament, nearly 86 percent of all bargains are mutually advantageous. Equal splits of payoffs rarely occurred. Therefore, issues of fairness require a context; a bargainer can be fair to a rival party or to the team of individuals who are dependent on his actions. The evidence suggests loyalties lie with the team.

In conclusion, testing the robustness of the Coase theorem under alternative scenarios is crucial in determining its potential usefulness in solving externality issues. This paper takes a step in exploring the boundaries of the Coase theorem. Uncertain payoff streams are probably the rule, suggesting continuing caution must remain about Coasian solutions. Future work should further explore the boundaries to determine the limits to which self-interested bargaining will lead to mutually advantageous, Pareto efficient externality levels regardless of initial property rights. 


\section{FOOTNOTES}

1. Other studies include Harrison and McKee (1985), Harrison et al. (1987), Hof fman and Spitzer (1985a, 1986), and Coursey et al. (1987).

2. Harrison et al. (1986) note three other sources of bargaining breakdown not incorporated into Coasian bargaining experiments. First, experimental contracts are perfectly enforced. Breach of contract was not an option to either of the two parties. Second, negotiation (or transaction) costs are assumed to be zero. Third, externalities were bilateral between the two bargaining parties. No third party was involved in either the damages or bargaining. Shogren and Kask (1990) have examined the impact of imperfect contract enforcement on bargaining efficiency.

3. Even in the private or limited information experiments of Hof fman and Spitzer (1982) the payoff streams were deterministic.

4. Harrison et al. (1986) note "[o]f course, to be confident about these possibilities for bargaining breakdown we would have to promulgate a model involving uncertainty and test it. Natural environments are likely to include such uncertainties, so we again counsel caution in directly applying our results."

[p. 400. Parentheses omitted].

5. As in Harrison and McKee (1985), we consider an "essentially equal split" as being agreements with an equal split or a split of $+/-\$ 1$ of the reward or $+/-10$ percent of the lottery tickets.

6. In our experiments, the Pareto efficient outcome always implies $\bar{p}=p+(1-p-Q)=1$. In other words, there is a 100 percent chance one of the two bargainers will win the large reward. This condition is not necessary, however, for Pareto efficiency. For example, it could be that $\bar{p}=p+(1-p-Q)=.95$ represents the Pareto efficient outcome $(Q=.05)$. This would hold as long as 95 percent yielded the highest expected payoff for both parties. An interesting extension of these bargaining experiments would be to consider bargaining where the Pareto efficient outcome is always less than 100 percent. Comparing those 
results to the results herein would provide a weak test of the generality of the so-called "certainty effect" discussed by Kahneman and Tversky (1979).

7. The "Winner's Curse" exists if a winner of a lottery or auction actually earns negative or less-than-expected profits when the monetary outcome of the lottery is revealed. See Thaler (1988a) for a discussion of the "Winner's Curse."

8. Actual experimental instructions are available from the author upon request or can be found in Shogren (1988).

9. See Nalebuff (1988) for further description of the dot game prebargain game trigger. The dot game is described in detail in the experiment instructions.

10. For the 80 percent lottery, the average certainty equivalent equaled $\$ 7.70$ with a range between $\$ 10$ and $\$ 5$. For the 90 percent lottery, the average certainty equivalent equaled $\$ 8.40$ with a range between $\$ 10$ and $\$ 6$.

11. Fairness in bargaining could also be considered a form of Kantian behavior where each bargainer acts as they want the other bargainer to act [see Laffont (1975) and Cornes and Sandler (1984)]. The controller may have acted as how he would have wanted the other party to act if he had not been the controller. This again could be the fault of the game trigger not inducing a belief of moral authority. 


\section{REFERENCES}

Binmore, K., Shaked, A. and Sutton, J. (1988). A Further Test of Noncooperative Bargaining Theory: Reply. American Economic Review 78: 837-40.

Boyer, M. and Dionne, G. (1983). Variations in the Probability and Magnitude of Loss: Their Impacts on Risk. Canadian Journal of Economics 16: 409-19.

Coase, R. (1960). The Problem of Social Cost. Journal of Law and Economics 3: 1-44.

Cornes, R. and Sandler, T. (1984). Easy Riders, Joint Production, and Public Goods. Economic Journal 94: 580-598.

Coursey, D., Hoffman, E., and Spitzer, M. L. (1987). Fear and Loathing in the Coase Theorem: Experiments Involving Physical Discomfort. Journal of Legal Studies 16: 217-48.

Frank, R. (1987). If Homo Economicus Could Choose His Own Utility Function, Would He Choose One with a Conscience? American Economic Review 77: 593-604.

Harrison, G. W., Hoffman, E., Rutstrom, E. E., and Spitzer, M. L. (1987). Coasian Solutions to the Externality Problem in Experimental Markets. Economic Journal 97: 388-402.

Harrison, G. W. and McKee, M. (1985). Experimental Evaluation of the Coase Theorem. Journal of Law and Economics 28: $653-70$.

Hoffman, E. and Spitzer, M. L. (1982). The Coase Theorem: Some Experimental Tests. Journal of Law and Economics 25: 73-98.

Hoffman, E. and Spitzer, M. L. (1985a). Entitlements, Rights, and Fairness: An Experimental Examination of Subjects' Concepts of Distribution Justice. Journal of Legal Studies 14: 25997.

Hoffman, E. and Spitzer, M. L. (1985b). Experimental Law and Economics: An Introduction. Columbia Law Review 85: 991-1036.

Hoffman, E. and Spitzer, M. L. (1986). Experimental Tests of the Coase Theorem with Large Bargaining Groups. Journal of Legal Studies 15: 149-71.

Kahneman, D. and Tversky, A. (1979). Prospect Theory: An Analysis of Decision Under Risk. Econometrica 47: 263-91.

Laffont, J-J. (1975). Macroeconomic Constraints, Economic Efficiency, and Ethics: An Introduction to Kantian Economics. Economica 42: 430-437. 
Murnighan, J. K., Roth, A., and Schoumaker, F. (1988). Risk Aversion in Bargaining: An Experimental Study. Journal of Risk and Uncertainty 1: 101-24.

Nalebuff, B. (1988). Puzzles: Penny Stocks, Discount Brokers, Better Bidding, and More. Journal of Economic Perspectives 2: 179-86.

Prudencio, Y. C. (1982). The Voluntary Approach to Externality Problems: An Experimental Test. Journal of Environmental Economics and Management 9: 213-28.

Roth, A. E. (1987). Laboratory Experimentation in Economics. Advances in Economic Theory (T. R. Bewley, editor). Cambridge: Cambridge University Press, 269-99.

Roth, A. E. (1988). Laboratory Experimentation in Economics: A Methodological Overview. Economic Journal 98: 974-1031.

Roth, A. and Malouf, M. (1979). Game-Theoretic Models and the Role of Information in Bargaining. Psychological Review 86: 574-94.

Rubinstein, A. (1982). Perfect Equilibrium in a Bargaining Game. Ecconometrica 50: 97-109.

Shogren, J. (1988). Valuing Risk in Experimental Markets: Self-Protection, Self-Insurance, and Collective Action. Final Draft Report for the U.S. Environmental Protection Agency CR814560-01-0.

Shogren, J. (1989). Fairness in Bargaining Requires a Context: An Experimental Examination of Loyalty. Economics Letters 31: 319-323.

Shogren, J. (1990). The Impact of Self-Protection and Self-Insurance on Individual Response to Risk. Journal of Risk and Uncertainty (forthcoming).

Shogren, J. and Kask, S. (1990). Imperfect Contract Enforcement and Bargaining Efficiency. Mimeo.

Siegel, S. (1956). Nonparametric Statistics for the Behavioral Sciences. New York: McGrawHill Book Co.

Thaler, R. (1988a). Anomalies: The Winner's Curse. Journal of Economic Perspectives 2: $191-$ 202.

Thaler, R. (1988b). The Ultimatum Game. Journal of Economic Perspectives 2: 195-206. 
Table 1

Alternative Lottery Schedules

\begin{tabular}{|c|c|c|c|c|}
\hline Schedule & Number & $\begin{array}{l}\text { A's Chance }^{\prime} \text { cha win }\left(\frac{8}{0}\right) \\
\text { to }\end{array}$ & $\begin{array}{l}\text { B's Chance } \\
\text { to win }(\%)\end{array}$ & $\begin{array}{l}\text { Joint } \\
\text { Chance }(\%)\end{array}$ \\
\hline \multirow[t]{7}{*}{$\mathrm{x}$} & 1 & 0 & 80 & 80 \\
\hline & 2 & 15 & 75 & 90 \\
\hline & 3 & 35 & 65 & 100 \\
\hline & 4 & 40 & 55 & 95 \\
\hline & 5 & 65 & 25 & 90 \\
\hline & 6 & 75 & 20 & 95 \\
\hline & 7 & 80 & 0 & 80 \\
\hline \multirow[t]{7}{*}{$\mathrm{Y}$} & 1 & 0 & 90 & 90 \\
\hline & 2 & 15 & 85 & 100 \\
\hline & 3 & 30 & 65 & 95 \\
\hline & 4 & 50 & 40 & 90 \\
\hline & 5 & 75 & 20 & 95 \\
\hline & 6 & 80 & 5 & 85 \\
\hline & 7 & 90 & 0 & 90 \\
\hline \multirow[t]{7}{*}{ Z } & 1 & 0 & 80 & 80 \\
\hline & 2 & 5 & 75 & 80 \\
\hline & 3 & 15 & 60 & 75 \\
\hline & 4 & 25 & 55 & 80 \\
\hline & 5 & 45 & 35 & 80 \\
\hline & 6 & 75 & 25 & 100 \\
\hline & 7 & 80 & 0 & 80 \\
\hline
\end{tabular}

NOTE: Joint chances to win (\%) were not provided to subjects. 
Iable 2

Experimental Results

\begin{tabular}{|c|c|c|c|c|c|c|c|c|c|c|}
\hline \multirow[b]{2}{*}{ Experiment } & \multirow[b]{2}{*}{ Lottery } & \multirow[b]{2}{*}{ Schedule } & \multirow[b]{2}{*}{$N$} & \multirow[b]{2}{*}{$\begin{array}{c}\text { Joint } \\
\text { Maximum }\end{array}$} & \multicolumn{6}{|c|}{ Poyoff Division } \\
\hline & & & & & $\begin{array}{l}\text { Equal } \\
\text { Sptit }\end{array}$ & $\begin{array}{l}+/-10 x \\
+/-\$ 1 \\
\end{array}$ & $\begin{array}{c}\text { Controller } \\
\text { Earns } \\
\text { Maximum } \\
\end{array}$ & $\begin{array}{l}\text { Controller } \\
\text { Earns More } \\
\text { Than Maximum }\end{array}$ & Disagreement & other \\
\hline \multicolumn{11}{|l|}{ Ex Ante } \\
\hline ASX & simple & $x$ & 10 & 10 & 5 & 2 & 0 & 0 & 0 & 3 \\
\hline ASY & Simple & Y & 6 & 4 & 3 & 2 & 0 & 0 & 0 & 1 \\
\hline $\operatorname{ACX}$ & Compound & $x$ & 8 & 7 & 4 & 2 & 1 & 1 & 0 & 2 \\
\hline $\mathrm{ACY}$ & Compound & $\gamma$ & 6 & 6 & 2 & 1 & 1 & 0 & 0 & 2 \\
\hline$A C Z$ & Compound & 2 & 4 & 3 & 2 & 1 & 1 & 0 & 0 & 0 \\
\hline$A C$ & & ALL & 18 & 16 & 8 & 4 & 3 & 1 & 0 & 2 \\
\hline Total (A) & & $A S+A C$ & 41 & 36 & 21 & 9 & 3 & 1 & 0 & 7 \\
\hline PCX & Compound & $x$ & 6 & 4 & 6 & 0 & 0 & 0 & 0 & 0 \\
\hline PCY & Compound & $y$ & 8 & 7 & 6 & 2 & 0 & 0 & 0 & 0 \\
\hline$P C Z$ & Compound & $z$ & 4 & 4 & 3 & 1 & 0 & 0 & 0 & 0 \\
\hline PC & & ALL & 18 & 15 & 15 & 3 & 0 & 0 & 0 & 0 \\
\hline Total (P) & & $P S+P C$ & 41 & 35 & 32 & 7 & 2 & 0 & 0 & 0 \\
\hline Grand Total & (A) + & $(P)$ & 82 & 71 & 53 & 16 & 5 & 1 & 0 & 7 \\
\hline
\end{tabular}


Table 3

statistical Tests of Propositions 3 and 4

Test

NuII

Chi-Square Test statistic:

Hypothesis

Pareto Optimality Equal split

Proposition P3

Ex Ante vs.

Ex Post Bargaining
$A S=P S^{\mathrm{A}}$
$0.025^{b}$
0.103
$A C=P C$
0.000
0.833
$A S+A C=P S+P C$
0.000
0.928

Proposition P4

Simple vs.

compound Lottery
$A S=A C$
$0.010^{\mathrm{c}}$
0.066
$P S=P C$
0.001
0.017
$A S+P S=A C+P C$
0.006
0.003

- AS-ex ante simple lottery, PS-ex post simple lottery, AC-ex ante compound lottery, PC-ex post compound lottery.

b - We cannot reject the null hypothesis for Proposition P3 with a $90 \%$ confidence level

c - We cannot reject the null hypothesis for Proposition P4 with a $90 \%$ confidence level

NOTE - See S. Siegel (1956) for an explanation of all statistical terminology. 